\title{
PENGARUH STRATEGI VAKSINASI KONTINU PADA MODEL EPIDEMIK SVIRS
}

\author{
TONAAS KABUL WANGKOK YOHANIS MARENTEK ${ }^{1}$
}

${ }^{1}$ Universitas Universal Batam, tonaasmarentek@gmail.com, tonaasmarentek@uvers.ac.id

\begin{abstract}
Abstrak
Penyebaran penyakit menular sangat berbahaya sehingga perlu diminimalisir. Vaksinasi adalah salah satu cara untuk meminimalisir penyebaran penyakit menular ataupun untuk memberantas penyakit. Berdasarkan proses vaksinasi terdapat dua strategi vaksinasi yaitu strategi vaksinasi kontinu dan strategi vaksinasi terputus. Penelitian ini membahas strategi vaksinasi kontinu pada model epidemik SVIRS, dari hasil analisis diperoleh dua titik tetap yaitu titik tetap bebas penyakit dan tititk tetap endemik dan juga suatu nilai ambang batas epidemik yaitu bilangan reproduksi dasar yang selanjutnya digunakan sebagai batasan untuk analisis selanjutnya. Ambang batas epidemik atau bilangan reproduksi dasar sepenuhnya bergantung pada strategi vaksinasi kontinu yang dilakukan. Jika strategi vaksinasi yang dilakukan berada diatas atau sama dengan tingkat vaksinasi minimum maka titik tetap bebas penyakit akan stabil asimtotik yang artinya penyakit tidak akan menyebar dan pada akhirnya penyakit akan hilang dari populasi. Sebaliknya, jika strategi vaksinasi kontinu yang dilakukan berada dibawah tingkat vaksinasi minimum maka titik tetap endemik akan stabil asimtotik sehingga penyakit akan menyebar dan menjadi endemik. Selain itu dari hasil simuasi yang dilakukan dengan perangkat lunak Mathematica diperoleh bahwa vaksinasi berpengaruh dapat menurunkan proporsi individu yang terinfeksi dari populasi dan dengan strategi vaksinasi yang tepat yaitu strategi yang dilakukan lebih dari atau sama dengan tingkat vaksinasi minimum akan berhasil mencegah penyebaran penyakit menular.
\end{abstract}

Kata Kunci: Model Epidemik, SVIR, Vaksinasi, Strategi, Kestabilan

\section{PENDAHULUAN}

Penyebaran penyakit menular memiliki pengaruh yang luar biasa pada kehidupan manusia. Setiap tahun jutaan orang meninggal karena berbagai penyakit menular. Sehingga perlu dikendalikan atau diminimalisir agar tidak terjadi epidemik salah satu caranya dengan melakukan program vaksinasi. Sehingga untuk mengetahui seberapa besar laju penyebaran suatu penyakit menular secara matematis adalah dengan membuat model matematika penyebaran penyakit menular atau model matematika epidemik. Pertama, pola epidemik dapat digambarkan secara matematis dengan menghampiri keadaan sebenarnya. Kedua, menganalisa pola epidemik melalui model yang telah dirumuskan. Kemudian menginterpretasikan hasil analisa ke dalam keadaan sebenarnya.

Vaksinasi adalah salah satu cara untuk mencegah atau meminimalisir penyebaran suatu penyakit menular. Dan kini vaksinasi rutin disediakan disemua negara-negara berkembang terhadap semua penyakit. Pemberantasan atau eradikasi penyakit cacar yang terakhir terlihat dalam kasus alami pada tahun 1977 telah dianggap sebagai keberhasilan paling spektakuler vaksinasi [1]. 
Menurut Ramali dan Pamoentjak [2], vaksin itu merupakan suspensi bibit penyakit yang hidup tetapi telah dilemahkan atau dimatikan untuk menimbulkan kekebalan aktif terhadap suatu penyakit sehingga dapat mencegah atau mengurangi pengaruh infeksi oleh organisme alami. Sedangkan untuk menyelesaikan proses vaksinasi biasanya ada jadwal yang berbeda untuk penyakit yang berbeda ataupun untuk penerima vaksin yang berbeda. Teori epidemik penyebaran penyakit menular secara matematis pertama kali di kemukakan oleh Kermack dan McKendrick pada tahun 1927 yaitu model epidemik SIR dan SIS. Dalam model SIR ataupun SIS menyatakan bahwa penyebaran penyakit digambarkan oleh modelmodel kompartemen. Model kompartemen SIR ataupun SIS dengan setiap huruf mengacu pada kompartemen dimana individu berada. Kompartemen tersebut adalah : Susceptible (S) yaitu kelompok individu yang sehat tetapi rentan terhadap penyakit, Infected (I) yaitu kelompok individu yang terinfeksi dan dapat sembuh dari penyakit dan Recovered $(\mathrm{R})$ yaitu kelompok individu yang telah sembuh dan kebal dari penyakit. Individu yang rentan dapat tertular penyakit karena adanya kontak antar individu yang rentan dengan individu yang terinfeksi.

Oleh karena itu secara matematis vaksinasi juga dapat dianggap sebagai penambahan kompartemen V (Vaccinated) secara alami ke dalam model SIR, SIS ataupun SIRS sehingga modelnya menjadi SVIR, SVIS maupun SVIRS. Model epidemik SVIRS ini, berdasarkan prosesnya terdapat dua strategi vaksinasi yaitu strategi vaksinasi yang kontinu (CVS) dan strategi vaksinasi yang terputus (PVS). Dimana strategi CVS dapat dikenali sebagai perilaku dari individu-individu rentan yang dilakukan vaksinasi secara terus menerus sedangkan strategi PVS adalah suatu proses vaksinasi yang dilakukan hanya sekali atau bisa juga lebih dari sekali tetapi dengan jangka waktu tertentu yang telah ditetapkan (musiman). Tulisan ini mengkaji mengenai pengaruh strategi vaksinasi kontinu pada model epidemik SVIRS dengan pendekatan matematis.

\section{TINJAUAN PUSTAKA}

\subsection{Model Epidemik SVIRS dengan Strategi Vaksinasi Kontinu}

Tailei Zhang dan Zhidong Teng [3] menambahkan kompartemen V ke dalam model SIRS sehingga menjadi model SIRVS dengan asumsi bahwa individu yang divaksinasi selain masih bisa terinfeksi mereka tidak akan mendapatkan kekebalan permanen tetapi akan langsung kembali ke populasi individu yang rentan. Xianning Liu et al. [4] menambahkan kompartemen V kedalam model SIR dan memperkenalkan strategi vaksinasi kontinu pada model epidemik SVIR, Alexander et al. [5] juga menambahkan kompartemen V kedalam model SIRS sehingga menjadi model SVIRS dengan asumsi bahwa individu tidak mendapatkan kekebalan dari proses vaksinasi, individu yang divaksinasi hanya memiliki kekebalan sementara sehingga langsung masuk ke populasi individu yang rentan dan individu yang mendapatkan kekebalan alami akibat sembuh dari penyakit masih memungkinkan untuk masuk ke populasi individu yang rentan karena kekebalan individu yang diperoleh dari penyakit akan berkurang oleh waktu. Sehingga individu yang telah sembuh akan menjadi rentan terhadap penyakit lagi.

Sehingga strategi vaksinasi kontinu pada model SVIRS ini berdasar pada model epidemik dasar untuk suatu penyakit yang tidak menyebabkan kematian (non fatal) serta berdasarkan pada Hethcote [6], Alexander et al.[7] serta Xianning Liu [8] :

1. Total Populasi berada pada tingkat konstan

2. Jumlah populasi diasumsikan cukup besar sehingga dapat dianggap sebagai variabel kontinu

3. Laju rekrutmen dan laju kematian alami populasi diasumsikan sama yaitu $\mu$

4. Laju transmisi/penularan penyakit ketika individu rentan berinteraksi dengan individu yang divaksinasi yaitu $\beta$

5. Laju pemulihan individu yang terinfeksi yaitu $\gamma$, sehingga $1 / \gamma$ adalah waktu ratarata individu terinfeksi atau menderita penyakit. 
6. Laju rata-rata $\left(\frac{1}{\gamma_{1}}\right.$ adalah waktu rata-rata) individu yang mengalami vaksinasi untuk mendapatkan kekebalan yaitu $\gamma_{1}$.

7. Sebelum memperoleh kekebalan, individu masih memiliki kemungkinan terinfeksi dengan laju transmisi $\beta_{1}$. Diasumsikan juga $\beta_{1}<\beta$ karena individu yang memperoleh vaksinasi mungkin memiliki kekebalan parsial selama proses vaksinasi.

8. Laju individu yang hilang kekebalan akibat terinfeksi yaitu $\theta$.

9. Laju individu yang rentan menerima vaksin atau laju individu rentan dipindahkan kedalam proses vaksinasi $\alpha$.

sehingga berdasarkan metode "Compartment Modelling", asumsi-asumsi diatas dapat digambarkan dalam bentuk diagram transfer sebagai berikut :

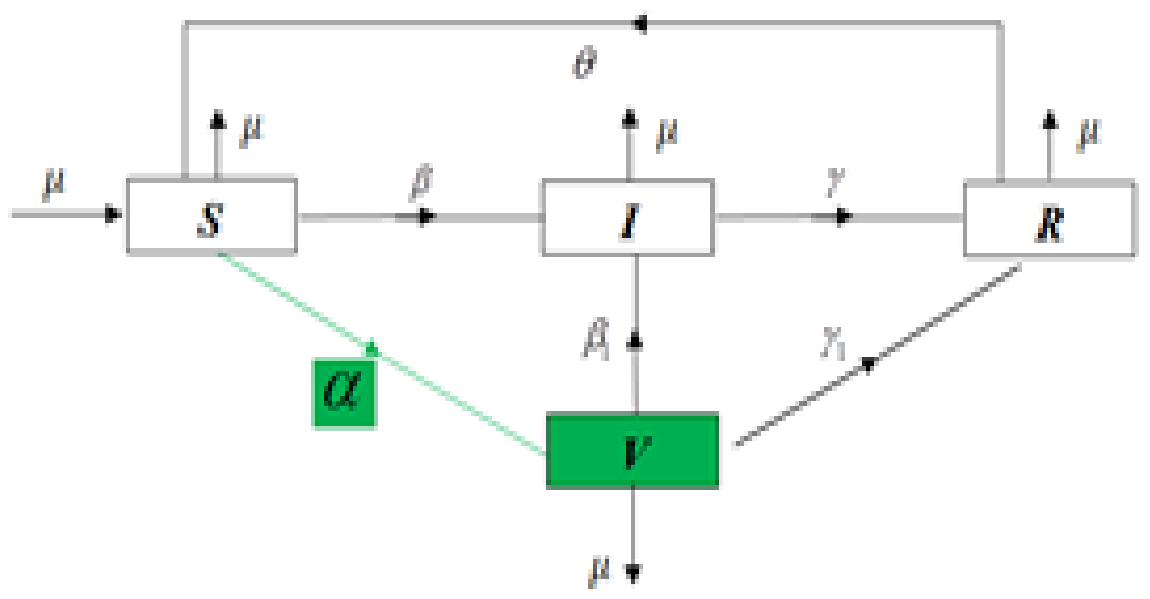

Gambar 1. Diagram Transfer Model Epidemik SVIRS

asumsi-asumsi dan diagram transfer diatas dapat dituliskan dalam bentuk persamaan diferensial linear yang selanjutnya disebut dengan sistem 1 sebagai berikut.

$$
\left\{\begin{array}{l}
\frac{d S}{d t}=\mu-\mu S-\beta S I-\alpha S+\theta R \\
\frac{d V}{d t}=\alpha S-\beta_{1} V I-\gamma_{1} V-\mu V \\
\frac{d I}{d t}=\beta S I+\beta_{1} V I-\gamma I-\mu I \\
\frac{d R}{d t}=\gamma_{1} V+\gamma I-\mu R-\theta R
\end{array}\right.
$$

dengan $\alpha, \theta \geq 0$ dan parameter lainnya bernilai positif.

\subsection{Metodologi Penelitian}

Dalam penelitian ini akan dilakukan dengan pendekatan matematis dan studi literatur. Adapun kerangka analisis penelitian ini adalah :

1. Menganalisis dinamika sistem dengan menentukan titik kesetimbangannya, memeriksa kestabilannya dan menentukan bilangan reproduksi dasarnya.

2. Menganalisis pengaruh vaksianasi kontinu berdasarkan bilangan reproduksi dasarnya secara matematis.

3. Mengimplementasikan dengan cara melakukan simulasi terhadap suatu contoh penyakit yang sesuai dengan model SVIRS (Mis. Influenza) dengan menggunakan perangkat lunak Mathematica 8 . 
Langkah-langkah penelitian secara rinci dapat dilihat pada Gambar 2 berikut :

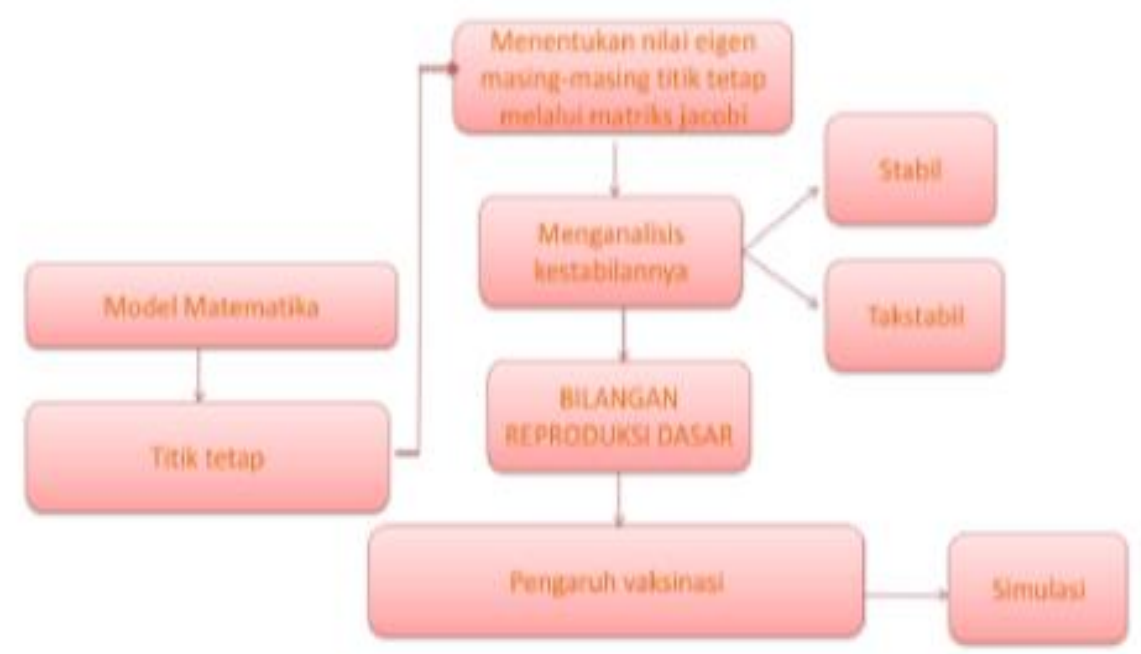

Gambar 2. Langkah-langkah penelitian.

\section{HASIL DAN PEMBAHASAN}

\subsection{Kestabilan Titik Tetap}

Titik tetap atau titik kesetimbangan adalah suatu kondisi setimbang pada populasi dimana terjadi "zero growth rate" atau tidak ada pertumbuhan pada masing-masing populasi. Jika $N=S+V+I+R$ adalah jumlah total populasi sehingga titik tetap ini diperoleh dengan mensubtitusikan $R=1-S-V-I$, maka Sistem 1 akan tereduksi menjadi Sistem 2 berikut.

$$
\left\{\begin{array}{l}
\frac{d S}{d t}=\mu-\mu S-\beta S I-\alpha S+\theta(1-S-V-I) \\
\frac{d V}{d t}=\alpha S-\beta_{1} V I-\gamma_{1} V-\mu V \\
\frac{d I}{d t}=\beta S I+\beta_{1} V I-\gamma I-\mu I
\end{array}\right.
$$

persamaan keempat pada Sistem 2 bebas dari ketiga persamaan lain maka titik tetap pada Sistem 2 diperoleh dengan membuat ketiga persamaannya sama dengan nol yaitu :

$$
\left\{\begin{array}{l}
\frac{d S}{d t}=0=\mu-\mu S-\beta S I-\alpha S+\theta(1-S-V-I) \\
\frac{d V}{d t}=0=\alpha S-\beta_{1} V I-\gamma_{1} V-\mu V \\
\frac{d I}{d t}=0=\beta S I+\beta_{1} V I-\gamma I-\mu I
\end{array}\right.
$$

\section{Titik Tetap Bebas Penyakit}

Misalkan titik tetap bebas penyakit diasumsikan $I_{0}=0$ yaitu tidak ada individu yang terinfeksi dalam populasi. Sehingga titik tetap bebas penyakit model ini adalah $T_{0}=\left(S_{0}, V_{0}, I_{0}\right)$ dengan $I_{0}=0$ dan

$$
S_{0}=\frac{(\mu+\theta)\left(\mu+\gamma_{1}\right)}{(\mu+\theta)\left(\mu+\gamma_{1}\right)+\alpha\left(\mu+\theta+\gamma_{1}\right)}, V_{0}=\frac{\alpha(\mu+\theta)}{(\mu+\theta)\left(\mu+\gamma_{1}\right)+\alpha\left(\mu+\theta+\gamma_{1}\right)}
$$

\section{Titik Tetap Endemik}

Misalkan $T_{+}=\left(S_{+}, V_{+}, I_{+}\right)$adalah titik tetap endemik dan diasumsikan bahwa dalam 
populasi masih terdapat individu yang terinfeksi dan dapat menyebarkan penyakit maka $I \neq 0$. Sehingga titik tetap endemik model ini dengan nilai $I$ adalah akar bernilai riil positif dari persamaan $g(I)$ yaitu $g(I) \equiv A_{1} I^{2}+A_{2} I+A_{3}$ dengan :

$A_{1}=\beta^{2}(\mu+\gamma)+\beta \beta_{1} \theta>0$

$A_{2}=\alpha \beta_{1}(\mu+\gamma+\theta)+\beta(\mu+\theta)\left\{2 \mu+\left(\gamma_{1}-\beta_{1}\right)\right\}+\beta \gamma\left(2 \mu+\gamma_{1}+\theta\right)>0$

$A_{3}=(-\beta+\gamma+\mu)\left(\mu+\gamma_{1}\right)(\mu+\theta)+\alpha\left\{-\beta_{1}(\mu+\theta)+(\mu+\gamma)\left(\mu+\theta+\gamma_{1}\right)\right\}$

dan

$S_{+}=\frac{\mu+\theta-\theta V_{+}-\theta I_{+}}{\mu+\alpha+\theta+\beta I_{+}}$serta $V_{+}=\frac{\alpha S_{+}}{\mu+\gamma_{1}+\beta_{1} I_{+}}$

\section{Analisis Kestabilan Titik Tetap}

Misalkan persamaan-persamaan pada Sistem 2 dituliskan dalam bentuk berikut :

$$
\begin{aligned}
& f(S, V, I)=\mu-\mu S-\beta S I-\alpha S+\theta-\theta S-\theta V-\theta I \\
& g(S, V, I)=\alpha S-\beta_{1} V I-\gamma_{1} V-\mu V \\
& h(S, V, I)=\beta S I+\beta_{1} V I-\gamma I-\mu I
\end{aligned}
$$

dengan melakukan pelinearan diperoleh matriks Jacobi sebagai berikut :

$$
J(S, V, I)=\left[\begin{array}{lll}
\frac{\partial f}{\partial S} & \frac{\partial f}{\partial V} & \frac{\partial f}{\partial I} \\
\frac{\partial g}{\partial S} & \frac{\partial g}{\partial V} & \frac{\partial g}{\partial I} \\
\frac{\partial h}{\partial S} & \frac{\partial h}{\partial V} & \frac{\partial h}{\partial I}
\end{array}\right]=\left[\begin{array}{ccc}
-(\mu+\alpha+\theta+\beta I) & -\theta & -\beta S-\theta \\
\alpha & -\beta_{1} I-\gamma_{1}-\mu & -\beta_{1} V \\
\beta I & \beta_{1} I & \beta S+\beta_{1} V-\gamma-\mu
\end{array}\right]
$$

Berdasarkan Borrelli dan Coleman [10], jika semua nilai eigen dari matriks Jacobi bagian riilnya bernilai negatif maka titik tetap tersebut stabil dan akan tidak stabil jika dan hanya jika satu saja nilai eigen matriks tersebut bagian riilnya bernilai positif. Namun, jika nilai eigen matriks Jacobi sulit ditentukan maka kestabilan titik tetap tersebut ditentukan dengan menggunakan kriteria Routh-Hurwits.

Hasil analisis kestabilan titik tetap :

1. Sistem 2 akan selalu mempunyai titik tetap bebas penyakit yaitu $T_{0}$ yang stabil asimtotik lokal jika $R_{d}<1$ dan akan tidak stabil jika $R_{d}>1$.

2. Sistem 2 akan mempunyai satu titik tetap endemik yang unik (hanya satu) yaitu $T_{+}$ jika dan hanya jika $R_{d}>1$ dan $T_{+}$akan stabil asimtotik lokal jika ada.

3. Terdapat $R_{d}$ yang adalah bilangan reproduksi dasar yaitu suatu bilangan yang menentukan kondisi Sistem ini. Dengan $R_{d}$ adalah :

$$
R_{d}=\frac{\beta(\mu+\theta)\left(\mu+\gamma_{1}\right)+\beta_{1} \alpha(\mu+\theta)}{(\mu+\gamma)(\mu+\theta)\left(\mu+\gamma_{1}\right)+\alpha\left(\mu+\theta+\gamma_{1}\right)(\mu+\gamma)}
$$

4. Keberadaan titik tetap endemik akan terpenuhi dan stabil asimtotik jika dan hanya jika $R_{d}>1$ dan Sistem 2 mempunyai dua titik tetap yaitu titik tetap bebas penyakit $T_{0}$ yang tidak stabil dan titik tetap endemik yang unik $T_{+}$yang stabil asimtotik lokal.

5. Kondisi titik tetap endemik $T_{+}$yang stabil asimtotik yang dipenuhi jika dan hanya jika $R_{d}>1$ mengartikan bahwa masih ada individu yang terinfeksi dalam populasi dan dapat menyebarkan penyakit sehingga pada akhirnya penyakit akan endemik dalam populasi. 


\subsection{Pengaruh Vaksinasi}

Hasil dari analisis kestabilan diatas menunjukan bahwa dinamika Sistem pada model ini sepenuhnya bergantung pada $R_{d}$ yaitu bilangan reproduksi dasar Sistem ini. Jika $R_{d}=1$ maka diperoleh tingkat vaksinasi minimum model ini yaitu :

$$
\alpha_{c}=\frac{(\beta-\gamma-\mu)(\mu+\theta)\left(\mu+\gamma_{1}\right)}{\left(\mu+\theta+\gamma_{1}\right)(\mu+\gamma)-\beta_{1}(\mu+\theta)}
$$

sehingga bilangan reproduksi dasar bergantung pada pengaruh dari strategi vaksinasi kontinu yang dilakukan. Jika $\alpha=0$ yaitu tidak dilakukannya proses vaksinasi maka $R_{d}$ akan tereduksi menjadi $R_{0}=\beta /(\mu+\gamma)$ yaitu bilangan reproduksi dasar jika tidak dilakukan proses vaksinasi. Ketika $R_{0} \leq 1$ maka penyakit dapat diberantas sehingga jika $R_{d} \leq R_{0}$ maka penyakit akan bisa diberantas dengan melakukan strategi vaksinasi kontinu. Sehingga untuk melihat pengaruh dari strategi vaksinasi kontinu pada model SVIRS diasumsikan bahwa jika $\alpha=0$ maka $R_{0}>1$ dan penyakit tidak dapat diberantas sehingga harus dilakukan proses vaksinasi $\alpha \neq 0$. Jika $\alpha>0$ atau dilakukan vaksinasi terdapat tiga kemungkinan strategi vaksinasi yang dilakukan yaitu $\alpha<\alpha_{c}, \alpha=\alpha_{c}$ dan $\alpha>\alpha_{c}$ dengan $\alpha_{c}$ adalah tingkat vaksinasi minimum.

\section{Strategi $\alpha>\alpha_{c}$}

Ketika strategi ini dilakukan akan menyebabkan $R_{d}<1$, sehingga hanya akan terdapat satu titik tetap yaitu titik tetap bebas penyakit $T_{0}$ yang stabil asimtotik lokal.

\section{Strategi $\alpha=\alpha_{c}$}

Ketika strategi ini dilakukan akan menyebabkan $R_{d}=1$ sehingga keberadaan titik tetap endemik $T_{+}$yang merupakan akar persamaan $g(I)$ yang bernilai riil positif tidak ada karena jika $R_{d}=1$ maka $A_{3}=0$, persamaan $g(I)$ tereduksi $g(I) \equiv A_{1} I^{2}+A_{2} I=\left(A_{1} I+A_{2}\right) I=0 \quad$ dan karena $A_{1}>0$ dan $A_{2}>0$ maka $g(I)$ tidak memilik akar yang bernilai riil positif. Keberadaan titik tetap bebas penyakit $T_{0}$ ketika $R_{d}=1$ akan menyebabkan semua nilai eigen bagian riilnya bernilai negatif kecuali nilai $\lambda_{3}=0$ sehingga $T_{0}$ akan ada dan stabil asimtotik. Sehingga, ketika $\alpha=\alpha_{c}$ maka $R_{d}=1$ tidak terdapat titik tetap endemik $T_{+}$dan hanya terdapat titik tetap bebas penyakit $T_{0}$ yang stabil asimtotik.

Strategi $\alpha<\alpha_{c}$

Ketika strategi ini dilakukan akan menyebabkan $R_{d}>1$, sehingga menurut hasil analisis kestabilan titik tetap diatas akan terdapat dua titik tetap yaitu titik tetap bebas penyakit $T_{0}$ yang tidak stabil dan titik tetap endemik $T_{+}$yang stabil asimtotik.

Dari analisis kestabilan dan strategi vaksinasi diatas dapat disimpulkan :

1. Jika strategi yang dilakukan $\alpha \geq \alpha_{c}$ akan menyebabkan $R_{d} \leq 1$ sehingga titik tetap bebas penyakit $T_{0}$ akan stabil asimtotik global.

2. Jika srategi yang dilakukan $\alpha<\alpha_{c}$ sehingga menyebabkan $R_{d}>1$ maka titik tetap endemik $T_{+}$stabil asimtotik global.

\subsection{Simulasi}

Untuk mengamati pengaruh dari strategi vaksinasi kontinu yang dilakukan terhadap model ini dilakukan simulasi numerik dengan bantuan perangkat lunak Mathematica 8 . 
Simulasi ini bertujuan untuk melihat pengaruh ketika dilakukan tiga strategi yang berbeda pada proses tersebut. Gambaran dari simulasi ini dalam bentuk kurva bidang solusi dari masing-masing populasi terhadap variabel waktu $(t)$.

Tabel 1. Nilai Parameter Simulasi

\begin{tabular}{|c|c|}
\hline Parameter & Nilai Parameter \\
\hline$S(0)$ & 0.6 \\
\hline$V(0)$ & 0.1 \\
\hline$I(0)$ & 0.3 \\
\hline$R(0)$ & 0 \\
\hline$\mu$ & 0.00003653 \\
\hline$\beta$ & 0.215 \\
\hline$\gamma$ & 0.143 \\
\hline$\beta_{1}$ & 0.1 \\
\hline$\gamma_{1}$ & 0.5 \\
\hline$\theta$ & 0.1 \\
\hline$\alpha$ & $\alpha>\alpha_{c}, \alpha=\alpha_{c}$ dan $\alpha<\alpha_{c}$ \\
\hline
\end{tabular}

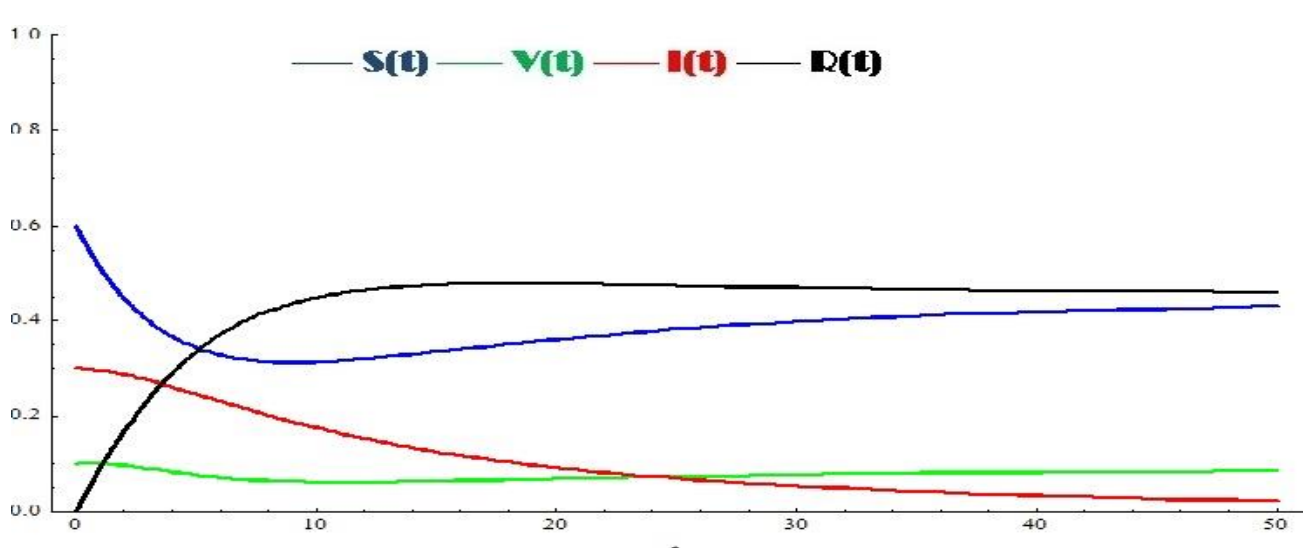

Gambar 3. Dinamika Populasi ketika $\alpha=0.1>\alpha_{c}=0.045474$

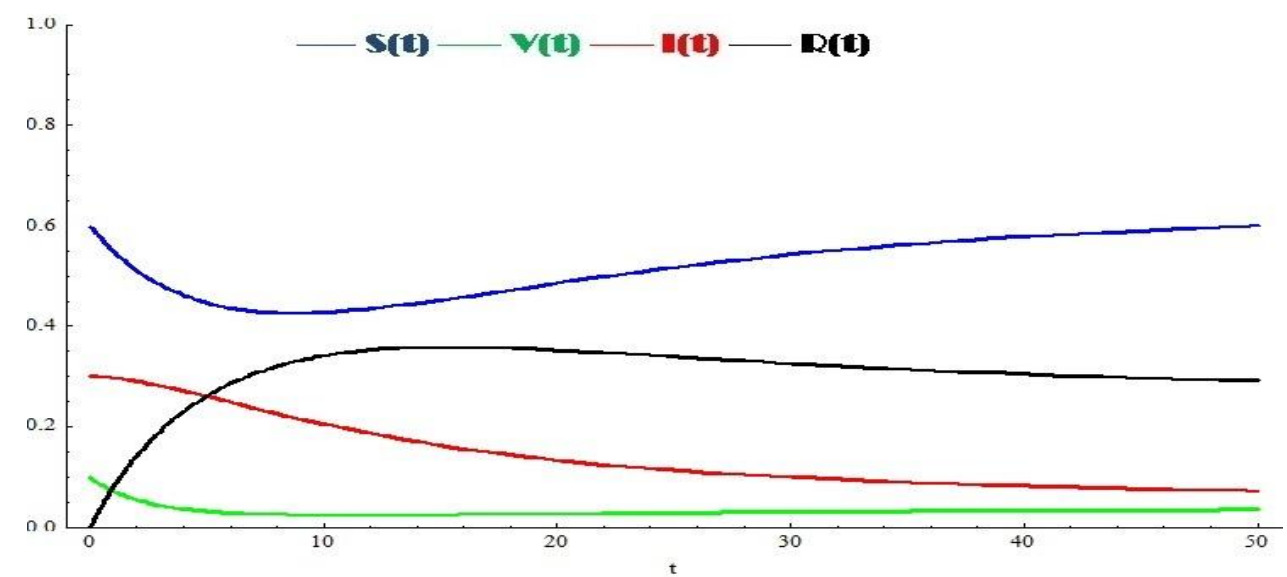

Gambar 4. Dinamika Populasi ketika $\alpha=0.03<\alpha_{c}=0.045474$

Gambar 3 menunjukan dinamika populasi dengan kondisi bebas penyakit. Kondisi ini terjadi ketika dilakukan strategi vaksinasi kontinu pada populasi individu rentan yaitu dengan $\alpha=0.1$ atau $10 \%$ dari jumlah populasi individu yang rentan divaksinasi setiap hari secara terus-menerus atau secara kontinu yang menyebabkan $R_{d}=0.75<1$. Kurva $S, V, I$ dan $R$ akan stabil menuju titik tetap bebas penyakit yaitu :

$$
T_{0}=\left(S_{0}, V_{0}, I_{0}, R_{0}\right)=(0.45,0.09,0,0.46)
$$


Proporsi individu yang terinfeksi (kurva merah) akan turun stabil menuju titik nol ketika dilakukan program vaksinasi dengan strategi $10 \%$ proporsi populasi rentan divaksinasi secara kontinu maka dapat strategi ini dapat memberantas penyakit. Sebaliknya, Pada Gambar 4 jika dilakukan strategi $\alpha=0.03$, menunjukan kondisi endemik yang tercapai, yaitu suatu kondisi masih tetap adanya penyakit dalam populasi. Kurva $S, V, I$ dan $R$ akan stabil menuju titik tetapnya yaitu

$$
T_{+}=\left(S_{+}, V_{+}, I_{+}, R_{+}\right)=(0.065,0.038,0.047,0.85)
$$

Proporsi individu yang terinfeksi (kurva merah) pada Gambar 4 akan turun dan stabil menuju titik 0.047 yang berarti bahwa ketika dilakukan program vaksinasi dengan strategi hanya $3 \%$ proporsi populasi rentan divaksinasi secara kontinu maka penyakit tidak bisa diberantas dan akan endemik tetapi dapat menurunkan proporsi individu yang terinfeksi.

Simulasi menunjukan pada Gambar 3 dan Gambar 4 diatas, dinamika populasi sistem ini terdapat dua kondisi yang berbeda. Pertama, kondisi bebas penyakit yang akan tercapai dengan melakukan strategi vaksinasi $\alpha=0.1$. Kedua, kondisi endemik ketika melakukan strategi vaksinasi $\alpha=0.03$. Strategi vaksinasi dengan $\alpha=0.03$ tidak dapat memberantas penyakit namun dapat menurunkan proporsi jumlah individu yang terinfeksi dalam populasi karena strategi ini berada dibawah ambang batas epidemik yaitu tingkat vaksinasi minimum $\alpha_{c}$ model ini. Nilai parameter $\alpha$ yang sangat mempengaruhi nilai $R_{d}$, dimana $\alpha$ adalah ambang batas strategi vaksinasi yang harus dilakukan secara kontinu pada individu yang rentan.

\section{KESIMPULAN}

\section{Simpulan}

Berdasarkan dari hasil dan pembahasan, diperoleh dua titik tetap yaitu titik tetap bebas penyakit dan titik tetap endemik. Dari analisis kestabilan, dinamika model SVIRS dengan strategi vaksinasi kontinu ini sepenuhnya bergantung pada bilangan reproduksi dasar. Ketika bilangan reproduksi dasarnya kurang dari atau sama dengan satu maka titik tetap bebas penyakit akan stabil asimtotik yang berarti bahwa penyakit tidak akan menyebar dalam populasi atau pada akhirnya penyakit akan hilang dari populasi. Jika bilangan reproduksi dasarnya lebih dari satu maka titik tetap endemik akan stabil asimtotik yang berarti bahwa penyakit akan tetap ada dan menyebar dalam populasi.

Selanjutnya, dari analisis dan simulasi terhadap pengaruh dari strategi vaksinasi kontinu diperoleh :

1. Diperoleh ambang batas atau tingkat vaksinasi minimum yang menjadi acuan strategi vaksinasi kontinu yang harus dilakukan.

2. Vaksinasi bermanfaat untuk mengendalikan penyebaran penyakit yaitu dengan mereduksi bilangan reproduksi dasarnya dan menurunkan proporsi individu yang terinfeksi pada tahap endemik.

3. Strategi yang dilakukan untuk memberantas penyakit harus lebih besar atau sama dengan tingkat vaksinasi minimum.

\section{Saran}

Penelitian ini perlu dilanjutkan dengan strategi vaksinasi yang berbeda yaitu strategi vaksinasi terputus dan membandingkan kedua strategi ini. Selain itu perlu juga dipertimbangkan efektifitas atau efikasi dari vaksin itu sendiri.

Setiap makalah diakhiri dengan kesimpulan, yang merangkum hasil dari makalah yang ditulis. 


\section{UCAPAN TERIMAKASIH}

Ucapan terima kasih saya ucapkan kepada seluruh pihak yang telah ikut membantu penelitian ini khususnya kepada Kemenristek Dikti atas bantuan dananya dan semua dukungannya.

\section{Daftar Pustaka}

[1] WHO. 2005. Immunization against diseases of public health importance. http://www.who.int/ mediacentre/factsheets/fs288/en/index.html/

[2] Ramali \& Pamoentjak. 2005. Arti dan Keterangan istilah. Kamus kedokteran.cet.26. Jakarta

[3] Tailei Zhang., Zhidong Teng., 2007. An SIRVS Epidemic Model With Pulse Vaccination Strategy. Journal of Theoretical Biology 250(2008) 375-381

[4] Xianning, L., Yasuhiro, T., Shingo, I., 2007. SVIR models with vaccination strategies. Shiuzuka University, Hammamatsu 432-9561, Japan

[5] Alexander, M.E., Bowman, C., Moghadas, S.M., Summers, R., Gumel, A.B., Sahai, B.M., 2004. A Vaccination Model for Transmission Dynamics of Influenza. SIAM J. Appl. Dyn. Syst. 3, 503-524

[6] Hethcote, HW., 2000. The mathematics of infectious diseases. SIAM rev.42. 599653

[7] Alexander, M.E., Bowman, C., Moghadas, S.M., Summers, R., Gumel, A.B., Sahai, B.M., 2004. A Vaccination Model for Transmission Dynamics of Influenza. SIAM J. Appl. Dyn. Syst. 3, 503-524

[8] Xianning, L., Yasuhiro, T., Shingo, I., 2007. SVIR models with vaccination strategies. Shiuzuka University, Hammamatsu 432-9561, Japan 